\title{
COMBINATION OF THE CHEMOTHERAPEUTIC AGENT 5-FLUORO- URACIL WITH AN INHIBITOR OF ITS CATABOLISM RESULTS IN INCREASED MICRONUCLEUS INDUCTION
}

\author{
Helga Stopper ${ }^{1}$, Anja Kühnel and Beate Podschun*
}

Institute of Pharmacology and Toxicology, University of Würzburg, 97078 Würzburg, Germany

* Theodor-Boveri-Institut für Biowissenschaften, Physiological Chemistry I, University of Würzburg, 97074 Würzburg, Germany

Recivel Augus 2, 19)4

The rate limiting step in 5-fluorouracil catabolism is catalyzed by the enzyme dihydropyrimidine dehydrogenase. Since degradation of 5-fluorouracil decreases its efficacy in chemotherapy, the inhibition of its catabolism is a promising tool. We investigated the formation of micronuclei in vitro in mouse L5178Y cells. 5-fluorouracil induced an increase in micronucleus frequency, which could significantly be enhanced by the concurrent application of 2,6-dihydroxypyridine, an inhibitor of dihydropyrimidine dehydrogenase. The 5-fluorouracil concentration necessary to reach maximal genotoxic effects could be reduced to half in the presence of inhibitor. 2,6-Dihydroxypyridine alone and the naturally occuring enzyme substrate uracil did not induce micronucleus formation. Combined application of the chemotherapeutic agent 5-fluorouracil and an inhibitor of its could reduce side-effects by lowering the effective dose of the active drug. With this study we provide further support for the usefulness of this concept. 1994 Academic press, Inc.

5-Fluorouracil and uracil are catabolized by the same enzymes. The first of a chain of three enzymes concerned with pyrimidine base catabolism in mammalians is DPD (EC 1.3.1.2). The enzyme was identified to catalyse the rate limiting step in this sequence $(1,2)$. Uracil or other 5-substituted pyrimidines like thymine or 5-FU are reduced in a NADPH-dependent reaction to the corresponding 5,6-dihydropyrimidines. The significance of this enzyme for chemotherapy stems from the fact that the widely used anticancer drug 5-FU which is administered in the treatment of various solid tumors including gastrointestinal, breast and ovarian carcinomas (3) is effectively catabolized and inactivated by the enzyme. The drug is usually administered by bolus i.v. injection or by continuous i.v. infusion. Humans with normal levels of DPD catabolize

\footnotetext{
1 Address correspondence to: Dr. Helga Stopper, Institute of Pharmacology and Toxicology, University of Würzburg, Versbacher Str. 9, 97078 Würzburg, Germany (Fax: 0931-201-3446).
}

Abbreviations: 5-FU, 5-fluorouracil; F-DHU, 5,6-dihydro-5-fluorouracil; DHP, 2,6dihydroxy-pyridin; DPD, dihydropyrimidine dehydrogenase; DTE, dithioerythriol. 
between $60 \%$ and $90 \%$ of the applied 5-FU. Therefore, inhibitors of this enzyme may be useful as chemotherapeutic agents by enhancing the antitumor activity of 5-FU. Most of the compounds that are used to inhibit enzymatic uracil reduction, are reduced by DPD. In contrast to these compounds the radiosensitizing drug 5 -jodouracil acts as suicide substrate by covalent modification of an active site cystein residue (4). 5-Ethynyluracil is an other mechanism-based irreversible inhibitor of DPD (5). It has been shown in rat and mouse models that 5-ethynyluracil potentiates the antitumor activity and the toxicity of 5-FU. The antitumor activity increases to a greater degree and thereby the therapeutic index of 5-FU increases 2- to 4-fold. In the extended list of ligands of DPD (6) one of the most effective inhibitors is DHP. It has strong inhibitory activity without acting as a substrate for the enzyme (7). DHP has been used in defining the kinetic mechanism of pig liver DPD (8). The enzyme processes the reactants (NADPH and e.g. uracil or 5-FU) at separate, nonoverlapping catalytic sites that are linked by an intermolecular electron transport chain. The pig liver enzyme is an excellent model for human DPD showing similar physical, kinetic and immunological properties (9).

We investigated 5-FU-induced micronucleus-formation in mouse L5178Y cells. This cell line has been shown to be suitable for analysis of micronucleus induction $(10,11)$. The main question was whether the genotoxicity of 5-FU could be enhanced in vitro by inhibiting 5-FU catabolism.

\section{Material and Methods}

Material: Bisbenzimide 33258 and 5-FU were obtained from Sigma, DHP was from Aldrich. F-DHU was generously supplied by Hoffmann-La Roche AG, Basel, Switzerland.

Cell culture: Mouse L5178Y cells, clone 3.7.2c, were cultured in suspension in RPMI-1640 supplemented with antibiotics, $0.25 \mathrm{mg} / \mathrm{ml} \mathrm{L}$-glutamine, $107 \mu \mathrm{g} / \mathrm{ml}$ sodium pyruvate and $10 \%$ heat inactivated horse serum (Sigma Chemie GmbH, Deisenhofen, Germany). Cell cultures were grown in a humidified atmosphere with $5 \% \mathrm{CO}_{2}$ in air at $37^{\circ} \mathrm{C}$.

In vitro micronucleus assay: Exponentially growing mouse $\mathrm{L} 5178 \mathrm{Y}$ cells which have a doubling time of 10 hours were treated for 4 hours. The vehicle control was 1\% DMSO. After removing the chemicals by centrifugation and medium replacement, the cells were incubated for 15 hours for dose-response experiments or for 0 to 25 hours for time course experiments (expression time). The cells were then brought onto glass slides by cytospin-centrifugation and were fixed with methanol $\left(-20^{\circ} \mathrm{C}, 1\right.$ hour $)$. For the staining of nuclei and micronuclei, the slides were washed with destilled water, incubated with bisbenzimide $33258(5 \mu \mathrm{g} / \mathrm{ml}, 3 \mathrm{~min}$.), washed three times with destilled water and mounted for microscopy. Using a magnification of 1250x the numbers of nuclei and micronuclei were scored. Each data point represents the mean of three slides with 2000 nuclei evaluated per slide. All experiments were repeated with consistent results.

Preparation of cell extracts: Cells in suspension were collected by centrifigation for $30 \mathrm{~min}$ at $10,000 \mathrm{~g}$. The cells were broken by hypotonic treatment in $10 \mathrm{ml}$ of homogenation buffer. In the control experiment the homogenation buffer contained $35 \mathrm{mM}$ potassium phosphate, $\mathrm{pH} 7.3$, $1 \mathrm{mM}$ DTE $(=$ buffer $\mathrm{A})$. In the other experiments cells were homogenized in a) buffer $A$ plus $9.75 \mu \mathrm{M} 5$-FU, b) buffer A plus $0.2 \mu \mathrm{M}$ DHP or c) buffer A plus $9.75 \mu \mathrm{M} 5$-FU and $0.2 \mu \mathrm{M}$ DHP. After centrifugation at $20,000 \mathrm{~g}$ for 30 min the supernatant fluid was concentrated to a volume of $1 \mathrm{ml}$ by ultrafiltration using centricon 10 devices (Amicon). All steps were performed at $4^{\circ} \mathrm{C}$. The concentrated fluids (cytosol) had protein contents of $10.11 \mathrm{mg} / \mathrm{ml}$ and were used for DPD assays as described (12). Protein was determined according to Schaffner and Weisman (13). 


\section{Results}

Micronucieus formation after treatment with 5-FU was investigated using mouse L5178Y cells. The micronucleus frequency increased in a dose dependent manner (Fig. 1a) and decreased after reaching a maximum at $19.5 \mu \mathrm{M}$. The time course of micronucleus formation after application of $19.5 \mu \mathrm{M}$ 5-FU (Fig. 1b) showed that the micronucleus frequency was optimal after an expression time of 15 hours. There was no visible toxicity at this time point, whereas some toxicity resulting in damaged nuclei could be seen at 25 hours. Cell growth was also impaired at 25 hours. This was reflected in a reduced cell number in the treated culture at the time of cell fixation to $33 \%$ compared to an untreated control culture. At 15 hours, cell number was $86 \%$ of the control. Therefore, an expression time of 15 hours was considered appropriate for further investigation of 5-FU-induced micronuclei.

Uracil, a naturally occuring substrate of DPD, did not induce micronuclei if applied under comparable conditions (Table 1). The pyrimidine-product (F-DHU) of the reaction catalysed by DPD was also investigated and was found not to induce micronuclei under comparable conditions (Table 1).

A putative enhancing effect of the inhibitor DHP on the micronucleus inducing capacity of 5-FU was investigated. DHP fits much better into the uracil binding site of DPD than 5-FU, as indicated by kinetic studies on the pig liver enzyme (8). The true $\mathrm{K}_{\mathrm{i}}$-value is $0.007 \mu \mathrm{M}$ for competition of DHP with the natural substrate uracil to bind at the pyrimidine binding site. In pig liver DPD the $\mathrm{K}_{\mathrm{m}}$-value for 5 -FU is $5.5 \mu \mathrm{M}$. Since the $\mathrm{K}_{\mathrm{m}}(5-\mathrm{FU}) / \mathrm{K}_{\mathrm{i}(\mathrm{DHP})}$ ratio is approximately 800, a much smaller concentration of DHP than 5-FU should inhibit the metabolising step sufficiently. However, interactions with components of the cell culture medium are possible and the most effective concentration had to be determined experimentally. First, it was examined whether DHP itself induced micronuclei (Table 1) and no induction was found within the dose range tested. At concentrations higher than $0.385 \mu \mathrm{M}$ some toxicity was seen
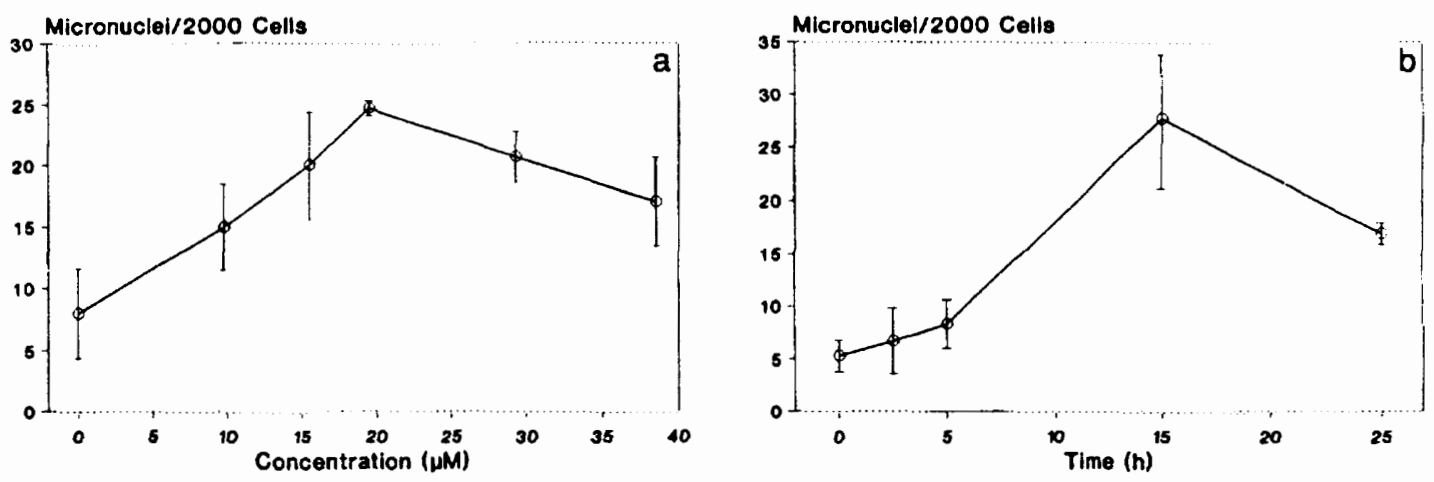

Figure 1. Dose response (a) and time course (b) of the micronucleus induction by 5-FU. Given are the time points after substance withdrawal. Control cultures showed $5.7 \pm 2.3$ micronuclei/ 2000 cells. Concentration of 5 -FU was $19.5 \mu \mathrm{M}$ in (b). 
Table 1: In vitro micronucleus assay

\begin{tabular}{lcc}
\hline Compound & $\begin{array}{c}\text { Conc of Varied } \\
\text { Compound }[\mu \mathrm{M}]\end{array}$ & Micronuclei/2000 Cells \\
\hline DHP & 0 & $6.3 \pm 0.6$ \\
& 0.385 & $70 \pm 2.7$ \\
& 0.77 & $4.3 \pm 1.5$ \\
& 3.85 & $6.0 \pm 1.0$ \\
77 & $5.3 \pm 0.6$ \\
& 385 & $7.3 \pm 0.6$ \\
F-DHU & 0 & $8.0 \pm 2.0$ \\
& 4.85 & $8.0 \pm 1.7$ \\
& 9.75 & $7.7 \pm 1.5$ \\
& 19.5 & $77 \pm 0.6$ \\
Uracil & 38.5 & $7.7 \pm 0.6$ \\
& 0 & $5.3 \pm 2.1$ \\
& 19.5 & $7.0 \pm 1.7$ \\
& 38.0 & $6.0 \pm 1.0$ \\
\hline
\end{tabular}

when measuring cell growth and trypan blue uptake (data not shown). As the result of an experiment, in which the concentration of 5-FU was kept at $9.75 \mu \mathrm{M}$ and the concentration of DHP was varied (Fig. 2a), $0.195 \mu \mathrm{M}$ DHP was chosen as being appropriate for further investigations.

The combination of DHP and 5-FU was further examined (Fig. 2b). While DHP alone again did not induce micronuclei, 5-FU did. The combination of both yielded the highest micronucleus frequency. This increase of micronucleus frequency was reproducible in 3 independent experiments (data not shown). As a final experiment, a dose response for micronucleus induction by 5-FU in the presence of DHP was performed (Fig. 3) and compared to that without DHP
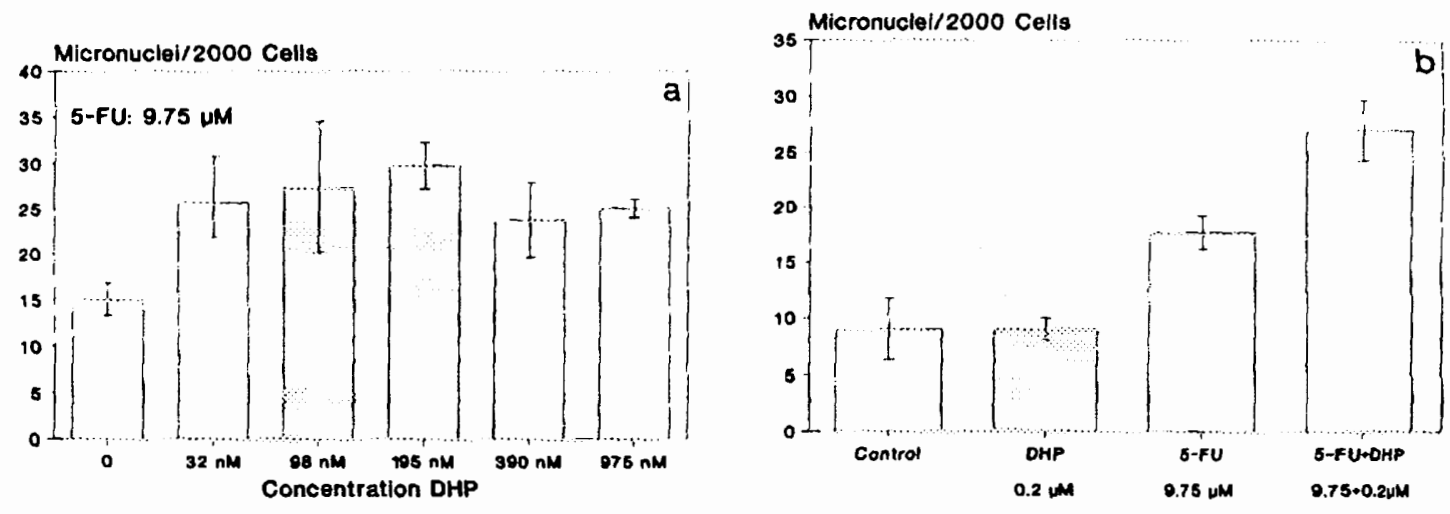

Figure 2. Micronucleus induction after treatment with 5-FU and DHP. (a) 5-FU concentration was constant $(9.75 \mu \mathrm{M})$ and the concentration of the inhibitor DHP was varied. A control culture without 5-FU or DHP showed $7.0 \pm 1.7$ micronuclei/2000 cells. (b) Each of the compunds was tested alone and in combination. 


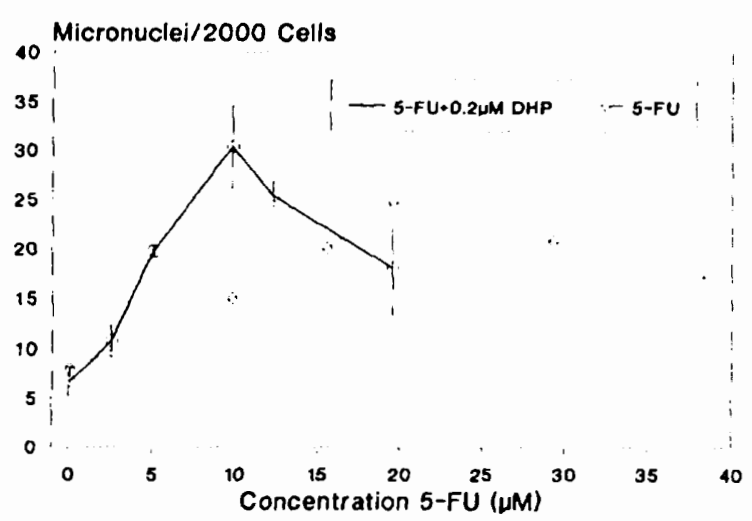

Figure 3. Dose response of the micronucleus induction by 5-FU with and without the addition of the metabolic inhibitor DHP.

(Fig. 3, narrow line; Fig. 1a). The 5-FU concentration necessary for maximum genotoxic effects was reduced to half in the presence of the inhibitor. It was shifted from $19.5 \mu \mathrm{M}$ to about $10 \mu \mathrm{M}$ in the presence of $0.195 \mu \mathrm{M}$ DHP together with a shift of the entire dose-response curve to smaller concentrations of 5-FU.

The specific activity of DPD in cytosolic extracts of mouse $25178 \mathrm{Y}$ cells was $0.00162 \mathrm{U} / \mathrm{mg}$ (control experiment). After treatment with DHP alone $(0.2 \mu \mathrm{M}, 4$ hours) and after treatment with a combination of 5-FU $(0.975 \mu \mathrm{M})$ and DHP $(0.2 \mu \mathrm{M})$ the activity of the catabolizing enzyme was below the detection limit. Under these conditions DHP inhibited the enzyme effectively.

\section{Discussion}

Micronuclei are DNA-containing structures in the cytoplasm of cells. They can contain chromosomal fragments or whole chromosomes which are surrounded by a membrane. Micronucleus frequency is a widely used genotoxicity endpoint for in vitro and in vivo studies and in the biomonitoring of human populations.

Micronucleus induction in mouse $25178 \mathrm{Y}$ cells after treatment with 5-FU decreased again after reaching a maximum at a certain time and dose. For the concentration dependence this may be due to toxicity of 5-FU and inhibition of cell cycle progression at higher doses. In fact, inhibition of cell growth as measured by cell counting and an increase in trypan blue uptake (data not shown) was observed at those higher concentrations. In the time course of micronucleus induction a delayed toxicity (some damaged nuclei at 25 hours) and a dilution of the micronucleus containing cell population with normal cells may both be responsible for the declining micronucleus frequency. Micronucleus induction by 5-FU has been described in vitro (14) and in vivo (15-17). 
5-FU induced micronuclei in L5178Y mouse cells, but neither its first metabolite F-DHU nor its naturally occuring analog uracil did. The genotoxic effect seems to be specific for the fluorosubstituted pyrimidine. The micronucleus induction does not reflect an effect of a total pyrimidine concentration.

In chemotherapy of solid tumors 5-FU exerts its cytotoxic effect mainly via thymidylate depletion, which leads to cell death. 5-Fluoro-2'-desoxyuridine-5'-monophosphate, an anabolite of the fluoropyrimidines, inhibits thymidylate synthase, an enzyme that catalyses the conversion of deoxyuridylate to thymidylate. Inhibition of thymidylate synthase results in a pronounced inhibition of DNA synthesis. Following its metabolism to 5-fluoro-2'-desoxyuridine-5'triphosphate, 5-FU is incorporated into DNA in certain cell types. Via metabolism to 5-fluorouridine triphosphate 5-FU is incorporated into cellular RNA in place of the normal metabolite, thus yielding fraudulent RNA. The incorporation of 5-FU into DNA and RNA may be summarized as genotoxicity of the drug. Since it is known that 5-FU is readily catabolized in mammalian celis and that this leads to a loss in the amount of active substance available in chemotherapy, we investigated whether addition of an inhibitor of the first step of 5-FU catabolism could enhance micronucleus induction by 5-FU. DHP has been shown to have excellent inhibitor properties in this respect. DHP itself proved to be unable to induce micronuclei, but its combination with 5-FU yielded an increased micronucleus frequency. The increase was independent of the DHP concentration within the tested range. Since DHP alone did not induce micronuclei even at much higher doses than those used for the combination experiments, a synergistic genotoxicity of the two compounds DHP and 5-FU is not a likely explanation for the increase in micronucleus frequency. Indeed, in the presence of DHP the activity of cytosolic DPD is inhibited. Therefore, the increase in micronucleus frequency was most likely due to inhibition of 5-FU catabolism. The dose response of 5-FU-induced micronuclei was shifted towards lower 5-FU concentrations in the presence of DHP. Under in vitro conditions DHP exerted no toxicity even at much higher concentrations than those necessary for the enhancement of micronucleus induction by 5 -FU. The experiments also demonstrate that data which may be useful for medical treatment can be achieved by applying the in vitro micronucleus assay as an endpoint for the effectiveness of a genotoxic agent.

Inhibitors of DPD were shown to potentiate certain effects of 5-FU in vitro and in vivo (18-23). In fact, an increase in antitumor activity by the use of a combination of a 5-FU derivative and 2,4-dihydroxypyridine in vivo has been reported by Fujii and Sakai (24). The mechanism-based inhibitor 5-ethynyluracil has been shown to be a potent modulator of the pharmacokinetics and antitumor efficacy of 5-FU in mice and rats (25). In the prescence of 5-ethynyluracil the toxicity of 5-FU increased about 10-fold. In mice treated with $2 \mathrm{mg} / \mathrm{kg}$ of 5-ethynyluracil p.o. in addition to $5-\mathrm{FU}$ for 9 days, the LD50 decreased from $45 \mathrm{mg} / \mathrm{kg} \mathrm{5-FU} \mathrm{(without} \mathrm{inhibitor)} \mathrm{to} 4 \mathrm{mg} / \mathrm{kg}$ 5-FU (in the presence of inhibitor). One part of the observed effect may be the result of an increased genotoxic action of 5-FU. As measured by micronucleus induction, the genotoxicity of 5-FU increased about 2-fold, when the pyrimidine catabolism was inhibited. Detailed mechanisms by which the toxicity of 5-FU increases after inhibition of catabolism may be 
difficult to evaluate because of the complex biochemical effects of 5-FU in normal and tumor cells.

These results are promising in view of a possible use of such a combination in chemotherapy. It might be possible to influence the other factors which lead to the additional toxicity in order to optimize the therapeutic index of 5-FU. With our study we could provide further support for the usefulness of the concept that the chemotherapeutic agent 5-FU may be combined with a compound able to inhibit one of the three pyrimidine catabolizing enzymes.

\section{Acknowledgments}

The authors are greatly indebted to Prof. K.D.Schnackerz for his kind support and continued interest. This work was supported in part by the Deutsche Forschungsgemeinschaft.

\section{References}

1.) Canellakis E.S (1956) J. Biol.Chem 221, 315-322.

2.) Queener, S.F.; Morris, H.P.; Weber, G. (1971) Cancer Res. 31, 1004-1009.

3.) Chabner, B.; Meyers, C.E. (1985) in: Cancer, Principles and Practice of Oncology (eds.: DeVita Jr, , V.T.; Hellman, S.; Rosenberg, S.A.), Lippincott, Philadelphia, 287-328.

4.) Porter, D.J.T.; Chestnut, W.G.; Taylor, L.C.E.; Merrill, B.M.; Spector, T. (1991) J. Biol. Chem. 266, 19988-19994.

5.) Porter, D.J.T.; Chestnut, W.G.; Merrill, B.M.; Spector, , T. (1992) J. Biol. Chem. 267, 5236-5242.

6.) Naguib, F.N.M.; el Kouni, M.; Cha, S. (1989) Biochem. Pharmacol. 38(9), 1471-1480.

7.) Tatsumi, K.; Fukushima, M.; Shirasaka, T.; Fujii, S. (1987) Jpn. J. Cancer Res. (Gann) 78, 748-755.

8.) Podschun, B.; Cook, P.F.; Schnackerz, K.D. (1990) J. Biol. Chem. 265, 12966-12972.

9.) Lu, Z.-H.; Zhang, R.; Diasio, R.B. (1993) Biochem. Pharmacol. 46(5), 945-952.

10.) Stopper, H.; Körber, C.; Schiffmann, D.; Caspary, W.J. (1993) Mutat. Res. 300, $165-$ 177.

11.) Stopper, H.; Eckert, I.; Schiffmann, D.; Spencer, D.L.; Caspary, W.J. (1994) Mutagenesis $9(5)$, in press.

12.) Podschun, B.; Wahler, G.; Schnackerz, K.D. (1989) Eur. J. Biochem. 185, 219-224.

13.) Schaffner, W.; Weissmann. C. (1973) Anal. Biochem. 56, 502-514.

14.) Matsuoka, A.; Yamazaki, N.; Suzuki, T.; Hayashi, M.; Sofuni, T. (1993) Mutat.Res. 272, 223-236.

15.) Maier, P.; Schmid, W. (1976) Mutat. Res. 40(4), 325-337.

16.) Collaborative Study Group for the Micronucleus Test (1990) Mutat. Res. 234, 205-222.

17.) Ohuchida, A.; Furukawa, A.; Yoshida, J.; Watanabe, M.; Aruga, F.; Miwa, Y.; Shinkawa, K.; Kinae, N. (1992) Mutat.Res, 278(2-3), 139-143.

18.) Cooper, G.M.; Dunning, W.F.; Greer, S. (1972) Cancer Res. 32, 390-397.

19.) Matthes, E.; Barwolff, D.; Langen, P. (1974) Acta Biol. Med. Germ. 32, 483-502.

20.) Desranges, C.; Razaka, G.; De Clercq, E.; Herdewijn, P.; Balzarini, J.; Drouillet, F.; Bricaud, H. (1986) Cancer Res. 46, 1094-1101.

21.) Iigo, M.; Araki, E.; Nakajima, Y.; Hoshi, A.; De Clercq; E. (1988) Biochem. Pharmacol. 37, 1609-1613.

22.) Daher, G.C., Naguib, F.M.N.; el Kouni, M.H.; Zhang, R.; Soong, S.J.; Diasio, R.B. (1991) Biochem. Pharmacol. 43(12), 1887-1893.

23.) Fujii, S.; Shimamoto, Y.; Ohshimo, H.; Imaoka, T.; Motoyama, M.; Fukushima, M.; Shirasaka, T. (1989) Jan. J. Cancer. Res. 80, 167-172.

24.) Fujii, S.; Sakai, Y. (1986) Jpn. Patent No. 61-109719, 165-176.

25.) Baccanari, D.P.; Davis, S.T.; Knick, V.C.; Spector, T. (1993) Proc. Natl. Acad. Sci. USA $20,11064-11068$. 